\title{
Anabases
}

ANABASES Traditions et réceptions de l'Antiquité

$26 \mid 2017$

Varia

\section{Ronald H. FRITZE, Egyptomania. A History of Fascination, Obsession and Fantasy}

Fabien Bièvre-Perrin

\section{OpenEdition}

Journals

Édition électronique

URL : http://journals.openedition.org/anabases/6257

DOI : $10.4000 /$ anabases. 6257

ISSN : 2256-9421

Éditeur

E.R.A.S.M.E.

Édition imprimée

Date de publication : 1 novembre 2017

Pagination : 234-236

ISSN : 1774-4296

Référence électronique

Fabien Bièvre-Perrin, «Ronald H. Fritze, Egyptomania. A History of Fascination, Obsession and Fantasy », Anabases [En ligne], 26 | 2017, mis en ligne le 01 novembre 2017, consulté le 20 janvier 2021. URL: http://journals.openedition.org/anabases/6257 ; DOI : https://doi.org/10.4000/anabases.6257

Ce document a été généré automatiquement le 20 janvier 2021.

(c) Anabases 


\section{Ronald H. FRITZE, Egyptomania. A History of Fascination, Obsession and Fantasy}

Fabien Bièvre-Perrin

\section{RÉFÉRENCE}

Ronald H. FRITZE, Egyptomania. A History of Fascination, Obsession and Fantasy, Londres, Reaktion Books, 2016, 448 p., 25 livres (31, 28 euros) / ISBN 978-1780236391.

1 Ronald H. Fritze, professeur d'histoire à l'Université d'Athens (Alabama), est principalement connu pour son approche critique de la pseudo-histoire, terme aujourd'hui délaissé en France au profit de l'appellation en vogue «fake science» (son ouvrage Invented Knowledge: False History, Fake Science and Pseudo-religions est paru en 2009).

2 Le chercheur américain se penche ici sur l'égyptologie et les différentes manières dont elle a été perçue, détournée, instrumentalisée... dans un ouvrage riche, synthétique et documenté. Fritze part de son expérience, et du constat selon lequel il était lui-même une victime de l'egyptomania. Son approche méthodique, tendant à l'exhaustivité est à saluer tant elle est rarement proposée, encore moins appliquée de façon scrupuleuse. En effet, les périodes anciennes sont souvent délaissées en raison de la rareté et de la difficulté des sources, et la période la plus contemporaine est négligée pour des raisons diverses et peu scientifiques: abondance voire démesure de la documentation, jugement négatif sur la culture de masse...

Concernant la forme, quelques réserves sont à formuler. Le livre est illustré de rares images en noir et blanc, quelquefois peu pertinentes et généralement privées de véritables légendes, ce qui est révélateur du peu d'intérêt de Fritze pour les aspects visuels. On peut également regretter que les notes soient regroupées en fin d'ouvrage, selon une numérotation discontinue qui rend leur consultation difficile, et qu'elles 
soient parfois trop peu nombreuses (une à deux par page en moyenne). Heureusement, un index permet de naviguer rapidement dans l'ouvrage.

Dans une brève introduction, Fritze propose de définir l'égyptomanie, ses causes («it is both comfortably familiar and intriguingly exotic.») et ses symptômes, souvent interchangeables. Il procède ensuite à un état des connaissances actuelles en égyptologie : un effort louable même si on pourrait y voir une confusion des genres. Le développement montre en effet que ce qui a retenu l'attention des créateurs et du grand public, provoquant donc l'egyptomania, coïncide rarement avec ce qui est considéré comme important par la communauté scientifique. Enfin, on plonge dans la longue histoire de ce phénomène, illustrant les rapports parfois tendus qu'entretiennent les scientifiques, les artistes et les affabulateurs depuis des siècles.

5 Le plan du livre est d'abord chronologique et offre à l'auteur l'occasion d'énumérer de nombreux faits et anecdotes peu connus. Dans la première partie, intitulée «Egyptomania through the Ages», le lecteur découvre la vision qu'avaient de l'Égypte les Hébreux, les Grecs et les Romains, puis parcourt le Moyen Âge, de saint Augustin à la Renaissance, qui fait l'objet d'un chapitre à elle seule (où l'on apprend par exemple que selon Annius de Viterbe, la famille Borgia avait pour ancêtre le dieu Osiris). Napoléon et la naissance de l'égyptomanie moderne, la découverte du tombeau de Toutânkhamon et les fantasmes qui entourent la malédiction des momies permettent enfin d'arriver progressivement à la période contemporaine. Dans les années 1820, le déchiffrement des hiéroglyphes par Champollion et d'autres linguistes est à considérer avec attention. Il s'agit en effet d'une étape clé dans l'histoire de la réception de l'Antiquité égyptienne : les vestiges deviennent alors assez soudainement parlants et l'imaginaire s'en trouve bouleversé. La présentation détaillée de ces éléments permet de bien appréhender les mutations culturelles et le rôle politique des références faites à l'Égypte dans la culture occidentale depuis l'Antiquité jusqu'à nos jours.

6 Dans la deuxième partie du livre, l'auteur délaisse son approche chronologique pour des sections thématiques: l'égyptomanie occulte, la pseudo-histoire (thème bien maîtrisé par Fritze, mais dont on peut questionner la pertinence dans un ouvrage dédié à l'égyptomanie comme phénomène culturel), l'afrocentrisme (mouvement noiraméricain cherchant à mettre en exergue l'identité singulière des cultures africaines et leurs apports à l'histoire de l'humanité, dont la présentation synthétique et renseignée de Fritze permet une meilleure compréhension de certains aspects de la culture de masse actuelle, malheureusement non abordée) et enfin le rapport de la fiction à l'égyptomanie, principalement dans la littérature et au cinéma. À l'exception d'un développement sur l'islam médiéval, Fritze se concentre sur l'Occident, et son rapport souvent coupable au passé impérialiste, délaissant la question des pays asiatiques pourtant passionnante, notamment en ce qui concerne le manga.

Plutôt qu'une conclusion, Fritze propose un court «postscript» de quatre pages sur l'actualité de l'égyptomanie, «alive and well», qui ne rend pas hommage à son travail, mais semble révéler une légère déconnexion de la culture populaire actuelle et des lacunes qui paraissent en partie inconscientes. En effet, cette non-conclusion explique la moindre qualité des développements consacrés à la période la plus contemporaine car si l'auteur parle certes des séries, il omet le cinéma, la musique, la mode, le jeuvidéo ou les subcultures, par ailleurs largement absents, hormis le cinéma, de l'ensemble de l'ouvrage. Il préfère illustrer la vivacité de l'égyptomanie par les courses de chevaux, 
les magazines d'histoire, les magasins d'antiquités ou les affabulations d'hommes politiques américains sur les pyramides.

Bien que la description prévale parfois sur l'analyse et que les lacunes sur la période récente soient regrettables, le livre de Fritze se distingue des nombreux autres ouvrages disponibles sur la question par son érudition et sa méthode. L'auteur ne recule donc pas devant l'ampleur de la tâche qu'il s'est assignée et tente ici de livrer un ouvrage synthétique sur l'egyptomania, agréable et accessible tout en demeurant savant et précis.

\section{AUTEURS}

\section{FABIEN BIÈVRE-PERRIN}

Aix-Marseille Université,

fabienbp@hotmail.com 